\title{
Association Between Vitamin D Levels and FEVI, Number of Exacerbations, and CAT Score in Stable COPD Patients in Indonesia
}

\author{
Arto Yuwono Soeroto (D) \\ Dadan Setiawan (iD ${ }^{2}$ \\ Nabila Nauli Asriputri (iD) 3 \\ Guntur Darmawan (D) ${ }^{4}$ \\ Geraldo Laurus iD ${ }^{3}$ \\ Prayudi Santoso (D) \\ 'Division of Respiratory and Critical \\ Illness, Department of Internal Medicine, \\ Faculty of Medicine Universitas \\ Padjadjaran, Hasan Sadikin General \\ Hospital, Bandung, Indonesia; \\ ${ }^{2}$ Department of Internal Medicine, \\ Occupational Health General Hospital, \\ Bandung, West Java, Indonesia; \\ ${ }^{3}$ Department of Internal Medicine, \\ Faculty of Medicine Universitas \\ Padjadjaran, Hasan Sadikin General \\ Hospital, Bandung, Indonesia; \\ ${ }^{4}$ Department of Internal Medicine, \\ Faculty of Medicine, Krida Wacana \\ Christian University, Jakarta, Indonesia
}

Correspondence: Arto Yuwono Soeroto $\mathrm{Tel}+628 \mathrm{II} 246930$

Email aysoeroto@yahoo.co.id
Purpose: This study aimed to assess the association between vitamin D levels and forced expiratory volume in one second (FEV1), number of exacerbations, and symptoms based on COPD assessment test (CAT) scores in stable COPD patients in Indonesia.

Patients and Methods: An observational cross-sectional study was conducted. Subjects were stable COPD patients who were treated at a pulmonary clinic in a tertiary referral hospital in West Java from March to June 2018.

Results: Thirty subjects were recruited this study with an average age $62 \pm 8$ years. The mean vitamin D level was $20.17 \pm 8.91 \mathrm{ng} / \mathrm{mL}$. Half of the patients had low vitamin D level (<20ng/ $\mathrm{mL})(50 \%)$. The mean FEV1 (\%) predicted value was 37.2 \pm 14 . The median exacerbation per year was $1(0-5)$ and symptoms based on CAT score was 14 (3-34). No correlation was found between vitamin D levels and FEV1 (\%) predicted value $(r=0.126, p=0.253)$. Vitamin $\mathrm{D}$ level was inversely correlated with number of exacerbations $(\mathrm{r}=-0.639, \mathrm{p}<0.001)$ and CAT $(\mathrm{r}=-0.802, \mathrm{p}<0.001)$

Conclusion: Low level of vitamin D was associated with more frequent exacerbation and higher CAT scores but was not associated with FEV1 (\%) predicted.

Keywords: COPD, vitamin D, FEV1, CAT score

\section{Introduction}

Chronic obstructive pulmonary disease (COPD) is a pulmonary disease characterized by persistent and progressive air flow resistance in the airways. ${ }^{1}$ The prevalence of COPD accounted for almost 272.5 million cases in $2017 .^{2}$ Based on World Health Organization, COPD caused 3.23 million deaths in 2019, making it as the third leading cause of death worldwide. ${ }^{3}$ Interestingly, in Indonesia, the prevalence of COPD was $3.7 \%$ in $2013 .^{4}$

Vitamin D plays an important role in the respiratory system. ${ }^{5}$ Low vitamin D levels could lead to disruption of pulmonary function, especially in patients with previous respiratory disorders. ${ }^{6}$ Patients with COPD often experience vitamin D insufficiency or deficiency, as it may causes unstable pulmonary state. ${ }^{7}$ Vitamin D status is better in South East Asia and Japan compared to the Middle East, China and India. Vitamin $\mathrm{D}$ deficiency is also more common in Middle Eastern countries adult than South East Asia countries. ${ }^{8}$ This may be due to most countries in South East Asia are close to the equator line, thus receiving more sunlight. ${ }^{9}$

Prior studies showed high prevalence of low level vitamin D in males with COPD. Low level vitamin $\mathrm{D}$ was shown to be associated with lower FEV1, 
exacerbation, and severity of disease. ${ }^{10-12}$ Our study aimed to identify the association between vitamin D levels and FEV1, number of exacerbations and CAT scores in both male and female stable COPD patients in Indonesia. To the best of our knowledge, this is the first study assessing the association of vitamin D with FEV1, number of exacerbations and symptoms based on CAT score in stable COPD patients in Indonesia.

\section{Materials and Methods}

\section{Study Design and Data Collection}

This observational analytical study was conducted with a cross sectional design. Subjects were stable COPD patients who had been diagnosed according to the 2017 GOLD criteria (FEV1/FVC $<70 \%$ ) and treated at the Pulmonary Clinic at Hasan Sadikin General Hospital, Bandung between March and June 2018. The study population as selected based on consecutive admissions. Exclusion criteria were a disease or conditions that may affect vitamin D levels and metabolism, such as diabetes mellitus, asthma, chronic kidney disease (CKD) of at least stage 3 with an estimated glomerular filtration rate (e-GFR) of less than $60 \mathrm{~mL} / \mathrm{min} / 1.73 \mathrm{~m}^{2}$, chronic liver disease, tuberculosis, patients with malabsorption syndromes, such as Crohn's disease, celiac disease, inflammatory bowel disease, or a history of gastrectomy or jejunoileostomy, malignant diseases, and subjects must not have taken vitamin D supplements in the previous 3 months. Detailed medical history was taken to assess the characteristics of each study subject, height and weight checks to assess BMI, interview history of exacerbations in the past year and symptoms based on CAT scores, as well as vitamin D and spirometry examinations. Serum vitamin D levels were measured using the Enzyme Linked Immunosorbent Assay (ELISA) method and divided into sufficiency or normal if the value $\geq 30 \mathrm{ng} /$ $\mathrm{mL}$, insufficiency if $20-29 \mathrm{ng} / \mathrm{mL}$ and deficiency if $<20 \mathrm{ng} / \mathrm{mL}{ }^{5}$ Spirometry tests were performed according to ATS standards ${ }^{13}$ to assess the FEV1 (\%) and FVC predicted by using CHESTGRAPH HI-101. Data were analyzed using bivariate analysis with Pearson correlation test or Spearman's rank correlation test when the criteria for Pearson correlation test were not fulfilled. Variables that were analyzed are FEV1 (\%) predicted, number of exacerbations per year and symptoms according to CAT score. The significance of the test results is determined if $\mathrm{p}<0.05$. Statistical analysis was performed using
Statistical Product and Service Solution (SPSS) 18.0 version for Windows. The size of the study sample was determined based on the formula to analyze the correlation between vitamin $\mathrm{D}$ and FEV1, vitamin $\mathrm{D}$ and the risk of exacerbation and vitamin $\mathrm{D}$ and symptoms based on CAT score. We use the correlation coefficient from previous study. ${ }^{10}$ The minimum sample required was 30 .

The study had been ethically approved by the Ethics Committee of Dr Hasan Sadikin Hospital, Bandung according to approval letter number LB.04.01/A05/EC/ $155 / \mathrm{V} / 201$. This study was conducted in accordance with the Declaration of Helsinki. Written informed consent was obtained from the subjects prior the commencement of the study.

\section{Results}

Baseline characteristics of the subjects are illustrated in Table 1.

A total of 30 subjects were included in this study, according to male gender as many as $25(83.3 \%)$ and females as many as $5(16.7 \%)$. The mean age of the subjects was $(62 \pm 8)$ years, with the youngest age being 50 years and the oldest 79 years. The mean vitamin D [25 (OH) D] level was $(20.17 \pm 8.91) \mathrm{ng} / \mathrm{mL}$ with the lowest level $7.30 \mathrm{ng} / \mathrm{mL}$ and the highest level $40.30 \mathrm{ng} / \mathrm{mL}$. Subjects who had vitamin D deficiency status numbered $15(50.0 \%)$.

There was no significant correlation between vitamin D levels and FEV1 (\%) predicted with $r=0.126$ and $p=$ 0.253 . Vitamin $D$ showed moderate correlation with number of exacerbations $(r=-0.639, p=<0.001)$. There was a strong correlation between vitamin $\mathrm{D}$ levels and symptoms based on CAT scores with $r=-0.802$ and $p=<0.001$. The correlation between vitamin D and FEV1 (\%) predicted, number of exacerbations and CAT score in stable COPD patients is shown in Table 2.

\section{Discussion}

The mean value of vitamin D levels in this study was $20.17 \pm 8.91 \mathrm{ng} / \mathrm{mL}$. A lower serum vitamin D level was demonstrated in the previous similar study conducted in Egypt $(11.94 \pm 7.66 \mathrm{ng} / \mathrm{mL}) .{ }^{10}$ This may be caused by several factors. In general, the higher prevalence of vitamin $\mathrm{D}$ deficiency relates to several issues, such as less vitamin D photosynthesis in response to UVB in individuals with darker skin, use of extensive skin coverage, and scarce exposure to sunlight which has often been described in individuals originating from the 
Table I Characteristics of Study Subjects

\begin{tabular}{|c|c|}
\hline & $\begin{array}{l}n(\%) \text { or Mean } \\
\quad \pm \text { SD }^{\mathrm{a}}\end{array}$ \\
\hline Age (years) & $62 \pm 8$ \\
\hline \multicolumn{2}{|l|}{ Gender } \\
\hline -Male & $25(83.3)$ \\
\hline -Female & $5(16.7)$ \\
\hline Body Mass Index $\left(\mathrm{kg} / \mathrm{m}^{2}\right)$ & $21.8 \pm 3.5$ \\
\hline \multicolumn{2}{|l|}{ Work Environment } \\
\hline -Indoor & $10(33.3)$ \\
\hline -Outdoor & $20(66.7)$ \\
\hline \multicolumn{2}{|l|}{ Smoking Status } \\
\hline -Yes & $25(83.3)$ \\
\hline$-\mathrm{No}$ & $5(16.7)$ \\
\hline \multicolumn{2}{|l|}{$\begin{array}{l}\text { Smoking Criteria (number of cigarettes per day } \\
x \text { years of tobacco use) }\end{array}$} \\
\hline -Light smokers $(<400)$ & II (44.0) \\
\hline -Moderate smokers (400-799) & $7(28.0)$ \\
\hline -Heavy smokers $(\geq 800)$ & $7(28.0)$ \\
\hline \multicolumn{2}{|l|}{ Vitamin [25(OH)D] levels (ng/mL) } \\
\hline Mean \pm SD & $20.17 \pm 8.91$ \\
\hline -Deficiency & $15(50.0)$ \\
\hline -Insufficiency & $9(30.0)$ \\
\hline -Sufficiency & $6(20.0)$ \\
\hline FEVI (predicted) \% & $37.2 \pm 14.7$ \\
\hline \multicolumn{2}{|l|}{ Number of exacerbations (per year) } \\
\hline Median (range) & I (0-5) \\
\hline \multicolumn{2}{|l|}{ Symptom (CAT score) } \\
\hline Median (range) & $14(3-34)$ \\
\hline
\end{tabular}

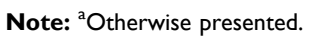

Abbreviations: FEVI, forced expiratory volume in one second; CAT, COPD assessment test.

Table 2 Correlation Between Vitamin D and FEVI (\%) Predicted, Number of Exacerbations and CAT Score in Stable COPD Patients

\begin{tabular}{|l|c|c|}
\hline & $\begin{array}{c}\text { Correlation } \\
\text { Coefficient (r) }\end{array}$ & p-value \\
\hline FEVI (\%) Predicted & $0.126^{\mathrm{a}}$ & 0.253 \\
Number of exacerbations & $-0.639^{\mathrm{b}}$ & $<0.00 I^{*}$ \\
Symptoms (CAT Score) & $-0.802^{\mathrm{b}}$ & $<0.00 I^{*}$ \\
\hline
\end{tabular}

Notes: *Statistically significant $(p<0.05)$. ${ }^{\text {a Pearson test. }}{ }^{\mathrm{b}}$ Spearman's rank correlation analysis.

Abbreviations: FEVI, forced expiratory volume in one second; CAT, COPD assessment test.

Middle East. ${ }^{14}$ Moreover, Indonesia is lying along the equator line, causing higher sunlight exposure than Egypt. ${ }^{9}$ These factors may in part explain why the prevalence of vitamin D deficiency is higher in the study by Gouda et al. ${ }^{10}$

Age may also play a role in this finding. In our study, the mean age was $62 \pm 8$ years and vitamin $\mathrm{D}$ intake derived from nutrients was not assessed. In the elderly, vitamin D deficiency was usually due to lack of intake of foods rich in vitamin $\mathrm{D}, 5,15,16$ although according to Wacker et al sunlight exposure plays a more important role in producing vitamin D. ${ }^{17}$

This study did not find a significant correlation between FEV1 (\%) predicted and vitamin D levels, although there was a positive trend; the higher the levels of vitamin D, the higher the FEV1 (\%) predicted. The results of this study were not in accordance with a previous study, in which there was a significant positive correlation between vitamin D levels and FEV1 (\%) predicted in stable COPD patients $(\mathrm{r}=0.548, \mathrm{p}=0.001) .{ }^{10}$ Janssens et al also found significant correlation between those two factors $(\mathrm{r}=0.28, \mathrm{p}<0.0001){ }^{12}$ Several factors may be the cause of this finding. This study did not assess other factors affecting pulmonary function as measured by FEV1, such as treatment, types of drugs used, and duration of treatment. The prior study also did not assess factors affecting pulmonary functions in patients with COPD, ${ }^{10}$ but based on the Toward a Revolutionary Study in COPD Health (TORCH), COPD treatment could slow the decline in FEV1. ${ }^{18}$ In the TORCH study, a decrease in FEV1 in study subjects receiving $\beta$-agonists (Salmeterol), Fluticasone, and a combination of Salmeterol/Fluticasone was around $27-31 \mathrm{~mL}$ per year, as compared to $56 \mathrm{~mL}$ in subjects receiving a placebo. Drugs used by study population were also important, as in the Understanding Potential Long-Term Impact on Function with Tiotropium (UPLIFT) study, subjects receiving Tiotropium as an anticholinergic for 4 years associated with improved lung function, quality of life and decreased exacerbation despite the reduction in FEV1 was not significant. ${ }^{19}$ Thus, study subjects who received adequate COPD treatment, despite having a vitamin D deficiency, the predicted FEV1 values could be higher than research subjects who had vitamin $\mathrm{D}$ deficiency and inadequate treatments. Furthermore, we did not assess the role of VDBP gene polymorphisms in our study. VDBP gene polymorphisms and vitamin $\mathrm{D}$ status are associated with clinical features of COPD patients. A previous study showed that COPD patients in Korea with GC2 polymorphism (estimation 2.46\%, $\mathrm{p}=0.050$ ) or $1 \mathrm{~F}-2$ genotype (estimation $3.31 \%, \mathrm{p}=0.015$ ) is associated with a low ratio $\mathrm{FEV} 1 / \mathrm{FVC}$, while $1 \mathrm{~F}-1 \mathrm{~F}$ 
genotype (estimation $3.61 \%, \mathrm{p}=0.018$ ) is associated with a high ratio FEV1/FVC. ${ }^{20}$ Additionally, vitamin D levels were found to be reduced in those carrying rs7041 GC variants and increased the risk for COPD severity $(\mathrm{p}=0.009){ }^{12}$

COPD exacerbation was mainly caused by microorganism infections that trigger the inflammatory process. Antimicrobial peptides such as cathelicidin are induced by the immune response to kill the microorganisms. Vitamin D stimulates the expression of cathelicidin in both myeloid and epithelial cells. With the antimicrobial function of cathelicidin associated with vitamin D levels, COPD exacerbations are reduced in patients with normal vitamin D levels compared to patients with vitamin D deficiency. ${ }^{7,15,16,21-23}$ This role of vitamin D was shown in our study; there was a significant correlation between vitamin $\mathrm{D}$ levels and the risk of exacerbation in patients with stable COPD at Hasan Sadikin General Hospital Bandung with a value of $r=-0.639$ and $p<0.001$. Malinovschi et al stated that COPD patients with severe vitamin D deficiency were associated with frequent exacerbations and hospitalization one year before measurement of vitamin D level. ${ }^{24}$ Another study also found a significant negative correlation between vitamin D levels and the risk of exacerbation in patients with stable COPD $(\mathrm{r}=-0.481, \mathrm{p}=0.007) .{ }^{10}$ Our findings are also aligned with previous study in India, in which COPD patients with vitamin $\mathrm{D}$ deficiency were tended to have more exacerbations three times fold. ${ }^{11}$

Low vitamin D level has been linked to inflammation modulation, impaired host defense, elevation of protease expression, and airway remodeling. ${ }^{25}$ An imbalance between protease and anti-protease was found in the lungs of patients with COPD. Protease works to break down connective tissue components and anti-protease works to inhibit the breakdown process. Some types of protease derived from inflammatory cells and epithelial cells were increased in number in patients with COPD. Protease, such as neutrophil elastase and matrix metalloproteinase including MMP-9, which are useful for the destruction of elastin, were major connective tissue components in the lung parenchyma. ${ }^{26}$ MMP-9 induced sputum production and degradation of the lung parenchyma, thereby worsening COPD symptoms. Vitamin D is also inversely linked to MMP-9 activity, in which vitamin D deficiency may enhance MMP-9 levels. ${ }^{22}$ Vitamin D acts as a suppressant for TNF- $\alpha$ so that MMP-9 activity will be reduced. The decrease in MMP-9 activity will have an impact on the reduction in COPD symptoms. ${ }^{10,16,21,22}$ In our study, there was a significant negative correlation between vitamin D levels and symptoms based on CAT scores in patients with stable COPD at Hasan Sadikin General Hospital Bandung with a value of $r=-0.802$ and $\mathrm{p}<001$. These results are in accordance with previous study with $\mathrm{r}=-0.468$ and $\mathrm{p}=0.009 .{ }^{10}$ In addition, a previous meta-analysis study showed a statistical significance of vitamin D therapy in COPD patient for improving the CAT score with $\mathrm{p}<0.01 .{ }^{27}$ Ringbaek et al found that the results of CAT, CCQ and SGRQ had a significant correlation with the severity of $\mathrm{COPD}^{28}$ A previous study by Agrawal et al also found that the quality of life (assessed by SGRQ) of COPD patients who fall into GOLD III and IV classification are worse than COPD patients who fall into GOLD I classification. ${ }^{29}$ Patients with COPD have shown to had disturbed physical function, poor balance and weak muscle; these conditions worsened in COPD patients with vitamin D deficiency, thus leading to low quality of life. ${ }^{30}$

The limitation of our study is that we did not evaluate confounding factors that affect vitamin D metabolism, such as nutritional intake, duration of sun exposure, parts of the body exposed to sunlight, and also the presence of VDBP gene polymorphisms. The exacerbation and CAT score were reported by the patients, so self-reporting bias is inevitable In addition, the subjects of our study are limited.

\section{Conclusion}

Our study showed that a low serum level of vitamin D was associated with higher number of exacerbations and symptoms based on CAT scores but was not associated with FEV1 (\%) predicted in Indonesian patients with stable COPD.

\section{Acknowledgments}

The authors wish to extend their thanks to all health professionals in the Pulmonary Clinic of the Hasan Sadikin General Hospital, Bandung who care for the patients.

\section{Funding}

The authors received no specific grant from an external source.

\section{Disclosure}

The authors report no conflicts of interest for this work and declare that there is no conflict of interest regarding publication of this article. 


\section{References}

1. Global Initiative for Chronic Obstructive Lung Disease. Global Strategy for the Diagnosis, Management, and Prevention of Chronic Obstructive Pulmonary Disease (2021 Report); 2021.

2. Viegi G, Maio S, Fasola S, Baldacci S. Global burden of chronic respiratory diseases. J Aerosol Med Pulm Drug Deliv. 2020;33 (4):171-177. doi:10.1089/jamp.2019.1576

3. World Health Organization. Chronic obstructive pulmonary disease (COPD); 2021. Available from: https://www.who.int/news-room/factsheets/detail/chronic-obstructive-pulmonary-disease-(copd). Accessed July 26, 2021.

4. Badan Penelitian dan Pengembangan Kesehatan. Riset Kesehatan Dasar. Kementerian Kesehatan RI; 2013.

5. Holick. Vitamin D Physiology, Molecular Biology, and Clinical Applications. 2nd ed. New York: Humana Press; 2010.

6. Ghosh AJ, Moll M, Hayden LP, Bon J, Regan E, Hersh CP. Vitamin $\mathrm{D}$ deficiency is associated with respiratory symptoms and airway wall thickening in smokers with and without COPD: a prospective cohort study. BMC Pulm Med. 2020;20(1):123. doi:10.1186/s12890-020-1148-4

7. Finklea JD, Grossmann RE, Tangpricha V. Vitamin D and chronic lung disease: a review of molecular mechanisms and clinical studies. Adv Nutr. 2011;2(3):244-253. doi:10.3945/an.111.000398

8. Lips P. Worldwide status of vitamin D nutrition. $J$ Steroid Biochem Mol Biol. 2010;121(1-2):297-300. doi:10.1016/j.jsbmb.2010.02.021

9. Nimitphong H, Holick MF. Vitamin D status and sun exposure in Southeast Asia. Dermato-Endocrinology. 2013;5(1):34-37. doi:10.4161/derm. 24054

10. Gouda E, Zidan M, Gharraf H, Younan DN, Mohamed S. Pattern of vitamin $\mathrm{D}$ in patients with chronic obstructive pulmonary diseases and in patients with bronchial asthma. Egypt J Chest Dis Tuberc. 2016;65(2):389-396. doi:10.1016/j.ejcdt.2016.02.005

11. Lokesh KS, Chaya SK, Jayaraj BS, et al. Vitamin D deficiency is associated with chronic obstructive pulmonary disease and exacerbation of COPD. Clin Respir J. 2021;15(4):389-399. doi:10.1111/crj.13310

12. Janssens W, Bouillon R, Claes B, et al. Vitamin D deficiency is highly prevalent in COPD and correlates with variants in the vitamin D-binding gene. Thorax. 2010;65(3):215-220. doi:10.1136/ thx.2009.120659

13. Miller MR, Hankinson JA, Brusasco V, et al. Standardisation of spirometry. Eur Respir J. 2005;26(2):319-338. doi:10.1183/ 09031936.05.00034805

14. Palacios C, Gonzalez L. Is vitamin D deficiency a major global public health problem? J Steroid Biochem Mol Biol. 2014;144:138-145. doi:10.1016/j.jsbmb.2013.11.003

15. Bikle DD. Vitamin D metabolism, mechanism of action, and clinical applications. Chem Biol. 2014;21(3):319-329. doi:10.1016/j. chembiol.2013.12.016

16. Kokturk N, Baha A, Oh YM, Young JJ, Jones PW. Vitamin $\mathrm{D}$ deficiency: what does it mean for chronic obstructive pulmonary disease (COPD)? A comprehensive review for pulmonologists. Clin Respir J. 2018;12(2):382-397.
17. Wacker M, Holick MF. Sunlight and vitamin D: a global perspective for health. Dermato-Endocrinology. 2013;5(1):51-108. doi:10.4161/ derm. 24494

18. Calverley PMA, Anderson JA, Celli B, Ferguson GT. Salmeterol and fluticasone propionate and survival in chronic obstructive pulmonary disease. $N$ Engl $J$ Med. 2007;356:775-789. doi:10.1056/ NEJMoa063070

19. Tashkin DP, Celli B, Senn S, Burkhart D. A 4-year trial of tiotropium in chronic obstructive pulmonary disease. $N$ Engl $J$ Med. 2008;359:1543-1554. doi:10.1056/NEJMoa0805800

20. Park Y, Kim YS, Kang YA, et al. Relationship between vitamin D-binding protein polymorphisms and blood vitamin $\mathrm{D}$ level in Korean patients with COPD. Int J COPD. 2016;11:731-738.

21. Ghoneim AH, Al-Azzawi MA, Elmasry SA, Nasr MY, AboZaid MMN. Association of vitamin D status in the pathogenesis of chronic obstructive pulmonary disease. Egypt J Chest Dis Tuberc. 2015;64:805-812. doi:10.1016/j.ejcdt.2015.06.004

22. Herr C, Greulich T, Koczulla RA, et al. The role of vitamin D in pulmonary disease: COPD, asthma, infection, and cancer. Respir Res. 2011;12:31. doi:10.1186/1465-9921-12-31

23. Hiemstra PS, de Jongh RT. Vitamin D deficiency in asthma and chronic obstructive pulmonary disease. a chicken-or-egg story. Am $J$ Respir Crit Care Med. 2020;202(3):312-313. doi:10.1164/ rccm.202004-1012ED

24. Malinovschi A, Masoero M, Bellocchia M, et al. Severe vitamin $\mathrm{D}$ deficiency is associated with frequent exacerbations and hospitalization in COPD patients. Respir Res. 2014;15:131. doi:10.1186/ s12931-014-0131-0

25. Ahmad S, Arora S, Khan S, et al. Vitamin D and its therapeutic relevance in pulmonary diseases. J Nutr Biochem. 2021;90:108571. doi:10.1016/j.jnutbio.2020.108571

26. Dey T, Kalita J, Weldon S, Taggart CC. Proteases and their inhibitors in chronic obstructive pulmonary disease. J Clin Med. 2018;7(9). doi: $10.3390 /$ jcm 7090244

27. Li X, He J, Yu M, Sun J. The efficacy of vitamin D therapy for patients with COPD: a meta-analysis of randomized controlled trials. Ann Palliat Med. 2020;9(2):286-297. doi:10.21037/apm.2020.02.26

28. Ringbaek T, Martinez G, Lange P. A comparison of the assessment of quality of life with CAT, CCQ, and SGRQ in COPD patients participating in pulmonary rehabilitation. COPD. 2012;9(1):12-15. doi:10.3109/15412555.2011.630248

29. Agrawal SR, Joshi R, Jain A. Correlation of severity of chronic obstructive pulmonary disease with health-related quality of life and six-minute walk test in a rural hospital of central India. Lung India. 2015;32(3):233-240. doi:10.4103/0970-2113.156231

30. Yumrutepe T, Aytemur ZA, Baysal O, Taskapan H, Taskapan CM, Hacievliyagil SS. Relationship between vitamin D and lung function, physical performance and balance on patients with stage I-III chronic obstructive pulmonary disease. Rev Assoc Med Bras. 2015;61 (2):132-138. doi:10.1590/1806-9282.61.02.132
International Journal of General Medicine

\section{Publish your work in this journal}

The International Journal of General Medicine is an international, peer-reviewed open-access journal that focuses on general and internal medicine, pathogenesis, epidemiology, diagnosis, monitoring and treatment protocols. The journal is characterized by the rapid reporting of reviews, original research and clinical studies across all disease areas. The manuscript management system is completely online and includes a very quick and fair peer-review system, which is all easy to use. Visit http://www.dovepress.com/ testimonials.php to read real quotes from published authors. 